\title{
Two-Dimensional Effects in Counterflow Methane Flames
}

\author{
R. Roe Burrell, Runhua Zhao, Dong Joon Lee, Hugo Burbano, Fokion N. Egolfopoulos \\ Department of Aerospace and Mechanical Engineering \\ University of Southern California, Los Angeles, California 90089-1453, USA
}

\begin{abstract}
The effect of flowfield geometry on flame propagation and extinction of atmospheric $\mathrm{CH}_{4} / \mathrm{N}_{2} /$ air flames was studied in the counterflow configuration. Laminar flame speeds and extinction strain rates for lean premixed and non-premixed flames were measured in axisymmetric burners producing either uniform or non-uniform axial velocity exit profiles. Particle image velocimetry was used to characterize the two-dimensional flowfield between the burners. The experiments were modeled with a onedimensional code and a detailed $\mathrm{C}_{2}$ hydrocarbon kinetic model. Laminar flame speeds were found to be insensitive to the burner exit velocity profile shape but extinction measurements were strongly affected. In non-uniform flows, two-dimensional flow field measurements revealed significant radial dependence of flow quantities and high-speed video captured off-center initiation of extinction. Thus, centerline measurements did not represent the extinction state properly, given the direct contradiction to onedimensional modeling assumptions, and the data was deemed unreliable for kinetic model validation. Flames in uniform flows were found to exhibit minimal radial dependence with extinction initiating at near-centerline locations.
\end{abstract}

\section{Keywords:}

Laminar flames; premixed flames; non-premixed flames; flame propagation; flame extinction 


\section{Introduction}

The counterflow configuration was developed in the 1950s and it has been an invaluable tool for experimental study of laminar flames (e.g., [1]) along with one-dimensional (1D) models (e.g., [2]-[5]) that were subsequently developed. At the same time, computational efficiency afforded by 1D models comes at the expense of generality; only carefully designed counterflow experiments are suitable for comparison. When properly implemented, counterflow flames may provide high quality flame data over a wide range of thermodynamic conditions [1], and such data contain important physical and chemical information.

Data from two classes of experimental burner design are widely compared to 1D modeling results; straight tube burners with flow conditioning screens (e.g., [6] and [7]) and high-contraction-ratio contoured burners (e.g., [8] - [11]). Both designs are idealized to produce plug-flow conditions and the data are modeled using 1D codes by imposing zero velocity gradient boundary conditions. Flows that generate sufficiently strong stagnation pressure fields deviate from plug-flow conditions and are characterized by velocity gradients at the burner exit, which should be included as boundary conditions in modeling. A strong stagnation pressure field is often suggested from observation of a "dimple" on the flame surface that is convex on the upstream side and indicates velocity non-uniformity at the burner exit.

Early studies seeking experimental verification of 1D modeling assumptions include that of Chelliah et al. [12], who identified plug flow boundary conditions in counterflow experiments, and Rolon and coworkers [13] who concluded that realistic flow fields could fail to reproduce plug flow conditions. Frouzakis et al. [14] and Park and Hamins [15] determined that results derived from 1D and axisymmetric two-dimensional (2D) simulations closely agree when uniform axial velocity exit profiles are implemented at the burner exit. Bergthorson and coworkers [16] investigated the accuracy of 1D modeling in contoured-nozzle-generated premixed flames and found agreements provided, in part, that 
the velocity boundary conditions were measured and implemented in the simulations. Oh et al. [6] used straight-tube burners with flow conditioning screens and found 1D-compatible centerline extinction for high strain rates but $2 \mathrm{D}$ effects for lower strain rates. Ji et al. [8] quantified the effect of boundary velocity gradients in contoured-nozzle extinction measurements. Sarnacki et al. [10] identified a stagnation pressure field of ellipsoidal geometry to be the physical mechanism causing departure from plug flow assumptions. Mittal et al. [17] attributed the departure from 1D behavior in non-uniform exit velocity profiles to the presence of temperature curvature at the system centerline as a result of flow non-uniformity. Bouvet et al. [11] studied contour-nozzle generated premixed flames and traced inconsistencies with 1D modeling to the assumption of constant pressure derivative eigenvalue. Niemann et al. [7] determined that straight tube burners with flow conditioning screens can reproduce 1D plug flow assumptions to within an accuracy of $5 \%$ in unreacting flows, allowing the use a oneparameter analytical description of the effective (global) strain rate [18] in lieu of local flow measurements. Johnson et al. [19] corroborated the assertion of Ref. 7 and further confirmed that contour-type burners are sufficiently modeled with 1D codes when appropriate boundary conditions are included.

In the present study, experiments and computations were performed to quantify the sensitivity of measured laminar flame speeds, $S_{u}^{0} \mathrm{~s}$, and extinction strain rates, $K_{\text {ext }}$, in lean premixed $\mathrm{CH}_{4} /$ air and $K_{\text {ext }}$ in non-premixed $\mathrm{CH}_{4}-\mathrm{N}_{2}$ /air flames to the velocity boundary conditions in straight-tube counterflow burners. The data were compared with 1D modeling results in order to assess their compatibility with 1D assumptions and highlight pitfalls for kinetic model validation. 


\section{Experimental approach}

The measurements were carried out in the counterflow configuration using straight-tube burners at atmospheric pressure and unburned reactant temperature $T_{u}=298 \mathrm{~K}$. Burner diameter, $D=21 \mathrm{~mm}$, and burner separation distance, $L=15.3 \mathrm{~mm}$, were chosen to mimic the geometry of Ref. 7 and allow for well-resolved velocity measurements. Flow conditioning screens were placed within the burner tubes and two configurations studied; burners with screens $\sim 5 D$ upstream from the exit, hereafter called Type A, and burners with an additional set of screens at the exit, called Type B. Flow velocities were measured using particle image velocimetry (PIV) and micron-size silicone oil as flow tracers produced by a pneumatic nebulizer (Meinhard HEN-170-A0.2). Direct flame imaging was obtained with a CMOS monochrome high-speed camera (Phantom v710). A system schematic is shown in Fig. 1.

The premixed flames studies were carried out in the symmetric twin-flame configuration (e.g. [20]) for lean $\mathrm{CH}_{4} /$ air mixtures. Non-premixed flames were established by counterflowing fuel/inert mixtures against air. $S_{u}^{0}$ and $K_{\text {ext }}$ were determined using flow velocity measurements along the stagnation streamline. A reference velocity, $S_{u, r e f}$, and a reference strain rate, $K_{r e f}$, were defined as the minimum axial velocity and maximum norm of the axial velocity gradient in the axial direction, respectively, ahead of the flame front (e.g., [1], [8], and [20]). Velocity and velocity gradient boundary conditions were measured and included in 1D simulations. $S_{u}^{0}$ was derived using a numerically-assisted, non-linear extrapolation approach (e.g., [8] and [21]-[24]). $K_{\text {ext }}$ was measured in both premixed and non-premixed flames by first establishing a near-limit flame and then gently reducing the fuel flow rate by up to $0.5 \%$ to achieve extinction (e.g., [8] and [21]-[24]). The uncertainty of the reported data was quantified based on repeated trials and is reported as $\pm 1 \sigma$ standard deviation from the mean value. Uncertainty in flow composition has been shown to be less than $0.5 \%$ [23].

\section{Modeling approach}


Detailed 1D modeling was based on the Sandia CHEMKIN [25] and Transport [26] subroutine libraries. Freely propagating flames were computed with the PREMIX code [3], while the counterflow flames were simulated using an opposed-jet code $[4,24]$. Both codes include radiation at the optically thin limit, Soret diffusion, and an updated description of $\mathrm{H}$ and $\mathrm{H}_{2}$ diffusion coefficients [27]. The stretched flame simulations accounted for the experimental boundary velocity gradients and for a finite a spatial domain of $15.3 \mathrm{~mm}$. The extinction states were computed by first establishing a vigorously burning flame and subsequently increasing the boundary velocity until flame extinction was approached. Near extinction, a two-point approach was employed whereby the problem is solved with exit velocity, and thus strain rate, as a dependent variable (e.g., [8]). All simulations employed the multicomponent transport formulation. The USC Mech II kinetic mechanism [28] was reduced to include only $\mathrm{H}_{2} / \mathrm{CO} / \mathrm{C}_{1}-\mathrm{C}_{2}$ species resulting in 38 species and 249 reactions. 


\section{Results and discussion}

\subsection{Flow fields}

Representative radial, $v_{r}$, and axial, $v_{x}$, velocity profiles for Type A and Type B burners were measured about $1 \mathrm{~mm}$ from the burner exit for an equivalence ratio $\phi=0.542$, normalized by $\left|v_{x}\right|_{\text {max }}$, and are compared in Fig. 2. It can be seen that, compared to Type B, Type A burners produce strong radial nonuniformity of $v_{x}$ as well as greater radial gradients of $v_{r}$, which due to continuity implies greater axial gradients of $v_{x}$. Neither configuration produces strictly plug-flow conditions but existing literature suggests that this may be accounted for in 1D modeling by including the experimental axial velocity gradients at the boundary.

Many details of the experimental flow field cannot be captured by centerline and boundary measurements, for example the distribution of $v_{r}$ and its radial gradient, as well as $v_{x}$ and its axial gradient as shown in Fig. 3. For the Type A burners shown in Fig. 3 (a-d), all flow quantities exhibit a radial dependence. Among those, $v_{x}$ and both velocity gradients are greatest in magnitude towards the outer edges of the flow field, although the radial variation of $v_{x}$ appears to diminish at $\mathrm{x} / \mathrm{D}$ locations downstream. Type B burners, Fig. 3 (e-h), exhibit notably less radial dependence; $v_{x}$ and both velocity gradients at the flame front are maximum in magnitude and nearly uniform over the central $50 \%$ of the radial domain. The radial non-uniformity of $v_{x}$ is an explicit violation of $1 \mathrm{D}$ modeling assumptions in which only $v_{r}$ is permitted to vary linearly with radius. 


\subsection{Laminar flame speeds}

Experimental and computed $S_{u}^{0}$ s for lean $\mathrm{CH}_{4} /$ air flames are shown in Fig. 4 along with select data from Ref. 29. The computations over-predict the measurements across the whole range of conditions studied while the measured $S_{u}^{0}$ s using either burner type and those reported in Ref. 29 are in agreement. Given combustion theory that suggests $S_{u}^{0} \sim \sqrt{\omega}$, where $\omega$ the overall reactivity, the results in Fig. 4 suggest that for the present conditions the experimentally observed reactivity is overpredicted by the computations. The kinetic model is known to overpredict the reactivity of lean $\mathrm{CH}_{4} /$ air flames (e.g., [29]), explaining thus the difference between computed and measured values.

As both Type A and Type B data are the same, the experimentally determined $S_{u}^{0}$ was found to be insensitive to the exit velocity profile shape, in apparent contradiction with the observations of Ref. 17. However, in Ref. 17 the differences between uniform and non-uniform exit velocity profiles were 3-5\% in $S_{u, r e f}$, which are within the experimental uncertainties, and up to $8 \%$ in $K_{r e f}$. For $\mathrm{CH}_{4} /$ air flames the Lewis number, $L e$, is slightly less than one and strain rate only weakly affects flame intensity. Thus the sensitivity of $S_{u}^{0}$ to variations in $K_{r e f}$ is small for low strain rate values [30, 31] and the overall uncertainty is dominated by $S_{u, r e f}$. These observations may not apply to flames with sufficiently large Le due to greater sensitivity of flame intensity to strain rate.

\subsection{Premixed flame extinction}

Experimental and computed $K_{\text {ext }}$ for lean, premixed $\mathrm{CH}_{4} /$ air flames are shown in Fig. 5(a). The simulation results again overpredict the data, which is consistent with the propagation results. Direct comparison of experimental results between different burner types is inappropriate because $K_{\text {ext }}$ increases with increasing boundary velocity gradient [8]. This effect is demonstrated in the modeling results of Fig. 5(a) where the increased boundary velocity gradients measured in Type A burners result in greater $K_{\text {ext }}$ values relative to Type B that exhibits milder exit velocity gradients. 
The $K_{\text {ext }}$ data obtained with different burner types were compared indirectly through 1D simulations. As $K_{\text {ext }} \sim \omega$ (e.g., [23]), the notable sensitivity of $K_{\text {ext }}$ to kinetics means that any uncertainties in its measurement could impact the validation of various rate constants in detailed kinetic models. The quantity $\frac{K_{\text {ext,sim }}}{K_{\text {ext,exp }}}$ can be interpreted as a comparison of the overall reactivity suggested by simulations to that measured reactivity; it approaches unity when simulations and experiments agree. Figure 5(b) depicts the variation of $\frac{K_{\text {ext,sim }}}{K_{\text {ext,exp }}}$ with $\phi$ and it can be seen that the predicted values exceed the measured ones, in Type A burners non-monotonically up to a factor of 2.4 and in Type B burners monotonically up to a factor of 1.7. The interpretation of the global reactivity based on the data derived in Type A and Type B burners differ, which suggests that at least one data set is incompatible with the 1D modeling results.

Given the sub-unity $\mathrm{Le}$ for $\mathrm{CH}_{4} /$ air mixtures, the flames are strengthened by increasing strain rate, merge at the stagnation plane, and become restrained from further movement whereupon insufficient chemical residence time leads to extinction [32]. It is also known that the flame surface follows the shape of the incoming flow field (e.g. [33]). Therefore, in nonuniform $v_{x}$ profiles generated by Type A burners (Figs. 2(a) and 3(b)), the flames will first approach the stagnation plane at locations away from the centerline where extinction then initiates. These flames can appear visually planar near extinction because symmetry and conservation of momentum dictate that axial flow velocity must approach zero close to the stagnation plane.

The dynamic behavior of the extinction process was captured with a high-speed camera and images are shown in Fig. 6. Time $t=0 \mathrm{~ms}$ corresponds to the moment the extinction process initiates. Extinction in Type A burners was found to initiate at a location away from the centerline, followed by transition to a propagating edge flame which momentarily surrounded the still-burning flame core, and eventually resulting in global extinction around $t=70 \mathrm{~ms}$; note that unavoidable minor asymmetry in 
the burner alignment caused the initiation of extinction on the right edge of the images. For Type B burners on the other hand, extinction initiates near the centerline before transitioning to an outwardly propagating edge flame followed by global extinction at $t=30 \mathrm{~ms}$. It should be noted that both burners produced apparently flat flame shapes, suggesting that a visual inspection of flame geometry is not sufficient to ensure flow field quality.

When extinction initiates on the centerline, the direction of edge flame propagation coincides with that of $v_{r}$ while for off-center extinction the edge flame propagates opposite to $v_{r}$. This resulted in the different time scales from initiation to completion of the extinction process, e.g. 30 vs. 70 ms, of Fig. 6; discussion on edge flame dynamics may be found in, e.g., Ref. 34.

Several physical mechanisms result in the trends observed in premixed flame extinction. Locally off-center extinction transitioning to global extinction in Type A burners produces $K_{\text {ext }}$ values that are systematically lower because the measured centerline velocity profiles are not representative of the extinction state. Additionally, the magnitude of flow non-uniformity has been shown [7] to scale with flow momentum and burner separation distance as $\rho v_{x}^{2}\left(\frac{D}{L}\right)^{2}$. For a fixed $L / D$, extinction of stronger flames (higher $\phi$ ) necessitates greater $v_{x}$. As isocontours of the stagnation pressure in counterflow are ellipsoidal in shape [10], the centerline velocity is preferentially decelerated compared to the edges, enhancing the exit velocity non-uniformity with increasing flow rate. There is also a buoyancy effect, which is typically negligible along the system centerline for all but the lowest strain rates. However, buoyancy can play an important role in the flame periphery even before the centerline is affected (e.g., [35]).

Based on this analysis, the differences of $K_{\text {ext }}$ values measured along the centerline of Type A and Type B burners is attributed to the non-uniformity of the incoming flow that causes off-center extinction initiation for the Type A burners. The difference between the data measured using Type B burners and computed $K_{\text {ext }}$ values is attributed to kinetic effects, as demonstrated in previous studies for lean 
$\mathrm{CH}_{4} /$ air flames (e.g., [29]). Consequently, the non-monotonic behavior for Type A flames shown in Fig. 5(b) may be explained by buoyancy for the lower $\phi$ s, which more directly affects the fluid mechanics of the jet outer edges. For higher $\phi \mathrm{s}$, the boundary flow non-uniformity increases with the flow rate as discussed earlier and the off-center extinction propensity is magnified. The conclusions derived for the near-unity $\mathrm{Le}_{\mathrm{CH}} /$ air flames are expected to hold for mixtures in which differential diffusion plays a more profound role.

\subsection{Non-premixed flame extinction}

Experimental and computed $K_{\text {ext }}$ for non-premixed $\mathrm{CH}_{4}-\mathrm{N}_{2} /$ air flames are shown in Fig. 7. As with premixed flame extinction, a direct comparison of the experimental results is inappropriate due to different boundary velocity gradients. As with premixed extinction, the notable sensitivity of nonpremixed $K_{\text {ext }}$ to kinetics [23] dictates that any uncertainties in its measurement could impact the validation of reaction rate parameters.

Data derived with Type B burners are within 30\% of the modeling predictions for all cases and the agreement is improved with increasing fuel mole fractions, $X_{C H 4}$. In contrast, the agreement between data derived in the Type A burners and predictions becomes notably less with increasing $X_{C H 4}$, up to a factor of 2.6. Similar to premixed flame extinction, the extinction of non-premixed flames initiates at off-center locations for Type A burners and at the center for Type B burners. The velocity gradients and strain rate distributions were determined to be similar to those shown in Fig 3. The relatively close agreement between the computed and measured $K_{\text {ext }}$ values in Type B burners does not contradict the results of Fig. 5(a) as the kinetic regimes are different. 


\section{Concluding remarks}

Laminar flame speeds and extinction rate rates of premixed $\mathrm{CH}_{4} /$ air flames and extinction strain rates of non-premixed $\mathrm{CH}_{4}-\mathrm{N}_{2} /$ air flames were measured in the counterflow configuration with burners producing at their exits either uniform or non-uniform axial velocity profiles. Experimental data were simulated with a one-dimensional code and a detailed $\mathrm{C}_{2}$ kinetic model. Inconsistencies were observed between one-dimensional modeling results and centerline extinction measurements in burners with nonuniform exit axial velocity profiles, leading to large disagreements between computed values and data. In burners with uniform exit axial velocity profiles, one-dimensional modeling was found to be appropriate for centerline extinction measurements and these measurements were in substantially better agreement with the computed values. The flame speed measurements were found to be insensitive to the burner exit axial velocity shape. Thus, the impact of flow field shape on the presently studied flame properties was demonstrated and the implication for validation of kinetic rate parameters was evaluated. Though analysis was limited to straight-tube burners, it is likely that the effects of flow non-uniformity could appear in any counterflow configuration where both the stagnation pressure gradients are sufficiently high and the location of flow-conditioning screens sufficiently far upstream from the burner exit. 


\section{Acknowledgements}

This material is based upon work supported as part of the CEFRC, an Energy Frontier Research Center funded by the U.S. Department of Energy, Office of Science, Office of Basic Energy Sciences under Award Number DE-SC0001198. Additional thanks to Mr. Christodoulos Xiouris for assistance with the high-speed videography and Prof. Paul D. Ronney for discussions on edge flame dynamics. 


\section{References}

[1] F.N. Egolfopoulos, N. Hansen, Y. Ju, K. Kohse-Höinghaus, C.K. Law, F. Qi, Prog. Energy Combust. Sci.43 (2014) 36-67.

[2] G. Dixon-Lewis, Proc. R. Soc. Lond. A 298 (1455) (1967) 495-513.

[3] R.J. Kee, J.F. Grcar, M.D. Smooke, J.A. Miller, A FORTRAN Program for Modeling Steady Laminar One-Dimensional Premixed Flames, Report No. SAND85-8240 Sandia National Laboratories, 1985.

[4] R.J. Kee, J.A. Miller, G.H. Evans, G. Dixon-Lewis, Symp. (Int.) Combust. 22 (1989) 1479-1494

[5] M.D. Smooke, Proc. Combust. Inst. 34 (2013) 65-98.

[6] C.B. Oh, A. Hamins, M. Bundy, J. Park, Combust. Theory Model. 12 (2) (2008) 283-302.

[7] U. Niemann, K. Seshadri, F.A. Williams, Combust. Flame 161 (2014) 138-146.

[8] C. Ji, E. Dames, Y.L. Wang, H. Wang, F.N. Egolfopoulos, Combust Flame 157 (2010) 277-287.

[9] J.M Bergthorson, S.D. Salisbury, P.E. Dimotakis, J. Fluid Mech. 681 (2011) 340-369.

[10] B.G. Sarnacki, G. Esposito, R.H. Krauss, H.K. Chelliah, Combust. Flame 159 (2012) 1026-1043.

[11] N. Bouvet, D. Davidenko, C. Chauveau, L. Pillier, Y. Yoon, Combust. Flame 161 (2104) 438-452.

[12] H.K. Chelliah, C.K. Law, T. Ueda, M.D. Smooke, F.A. Williams, Symp. (Int.) Combust. 23 (1990) 503-511.

[13] J.C. Rolon, D. Veynante, J.P. Martin, Expts. Fluids 11 (1991) 313-324.

[14] C.E. Frouzakis, J. Lee, A.G. Tomboulides, K. Boulouchos, Symp. (Int.) Combust. 27 (1998) 571577.

[15] W.C. Park, A. Hamins, KSME Int. Jour. 16 (2) (2002) 262-269. 
[16] J.M Bergthorson, D.G. Goodwin, P.E. Dimotakis, Proc. Combust. Inst. 30 (2005) 1637-1644.

[17] V. Mittal, H. Pitsch, F. Egolfopoulos, Combust. Theory Model. 16 (3) (2012) 419-433.

[18] K. Seshadri, F.A. Williams, Int. J. Heat Mass Transfer 21 (1978) 251-253,

[19] R.F. Johnson, A.C. VanDine, G.L. Esposito, H.K. Chelliah, Combust. Sci. Tech. 187 (2015) 37-59.

[20] O. Park, P.S. Veloo, F.N. Egolfopoulos, Proc. Combust. Inst. 34 (2013) 711-718

[21] P.S. Veloo, Y.L. Wang, F.N. Egolfopoulos, C.K. Westbrook, Combust. Flame 157 (2010) 19892004.

[22] Y.L. Wang, A.T. Holley, C. Ji, F.N. Egolfopoulos, T.T. Tsotsis, H.J. Curran, Proc. Combust. Inst. 32 (2009) 1035-1042.

[23] C. Ji, Y.L. Wang, F.N. Egolfopoulos, J. Prop. Power 27 (4) (2011) 856-863.

[24] F.N. Egolfopoulos, Symp. (Int.) Combust. 25 (1994) 1375-1381.

[25] R.J. Kee, F.M. Rupley, J.A. Miller, Chemkin-II: A Fortran Chemical Kinetics Package for the Analysis of Gas-Phase Chemical Kinetics, Report No.SAND89- 8009, Sandia National Laboratories, 1989.

[26] R.J. Kee, J. Warnatz, J.A. Miller, A FORTRAN Computer Code Package for the Evaluation of Gas Phase Viscosities, Conductivities and Diffusion Coefficients, Report No. SAND83-8209, Sandia National Laboratories, 1983.

[27] Y. Dong, A.T. Holley, M.G. Andac, Combust. Flame 142 (2005) 374-387.

[28] H. Wang, X. You, A.V. Joshi, et al., USC Mech Version II. High Temperature combustion Reaction Model of $\mathrm{H}_{2} / \mathrm{CO} / \mathrm{C}_{1}-\mathrm{C}_{4}$ Compound, 2007, available at http://www.ignis.usc.edu/USC_Mech_II.htm.

[29] O. Park, P.S. Veloo, N. Liu, F.N. Egolfopoulos, Proc. Combust. Inst. 33 (2011) 877-894. 
[30] J. Jayachandran, R. Zhao, F.N. Egolfopoulos, Combust. Flame 161 (2014) 2305-2316.

[31] J. Jayachandran, A. Lefebvre, R. Zhao, F. Halter, E. Varea, B. Renou, F.N. Egolfopoulos, Proc. Combust Inst. 35 (2015) 695-702.

[32] C.K. Law, Combustion Physics, Cambridge University Press, New York, NY, U.S.A, 2006, p. 410.

[33] C.M. Vagelopoulos, F.N. Egolfopoulos, Symp. (Int.) Combust. 27 (1998) 513-519.

[34] M.S. Cha, P.D. Ronney, Combust. Flame 146 (2006) 312-328.

[35] L. Figura, A. Gomez, Combust. Flame 159 (2012) 142-150. 


\section{Figure Captions:}

Figure 1: Schematic of the experimental system as configured for symmetric, premixed flames.

Figure 2: Flow velocity profiles measured $1 \mathrm{~mm}$ from the burner exit near extinction for $\phi=0.542$ : (a) Type A and (b) Type B burners.

Figure 3: Comparison of normalized flow field structure near extinction for $\phi=0.542$ Type A burner (ad) and Type B burners (e-h). Lightest (darkest) color corresponds to maximum (minimum) value.

Figure 5: Extinction strain rates of premixed CH4/air mixtures: (a) measured and computed results and (b) ratio of computed to measured values.

Figure 6: Evolution of the extinction process for lean CH4/air flames produced by Type A (a-d) and Type B (e-h) burners.

Figure 7: Extinction strain rates of non-premixed CH4-N2/air flames. (a) measured and computed results and (b) ratio of computed to measured values. 


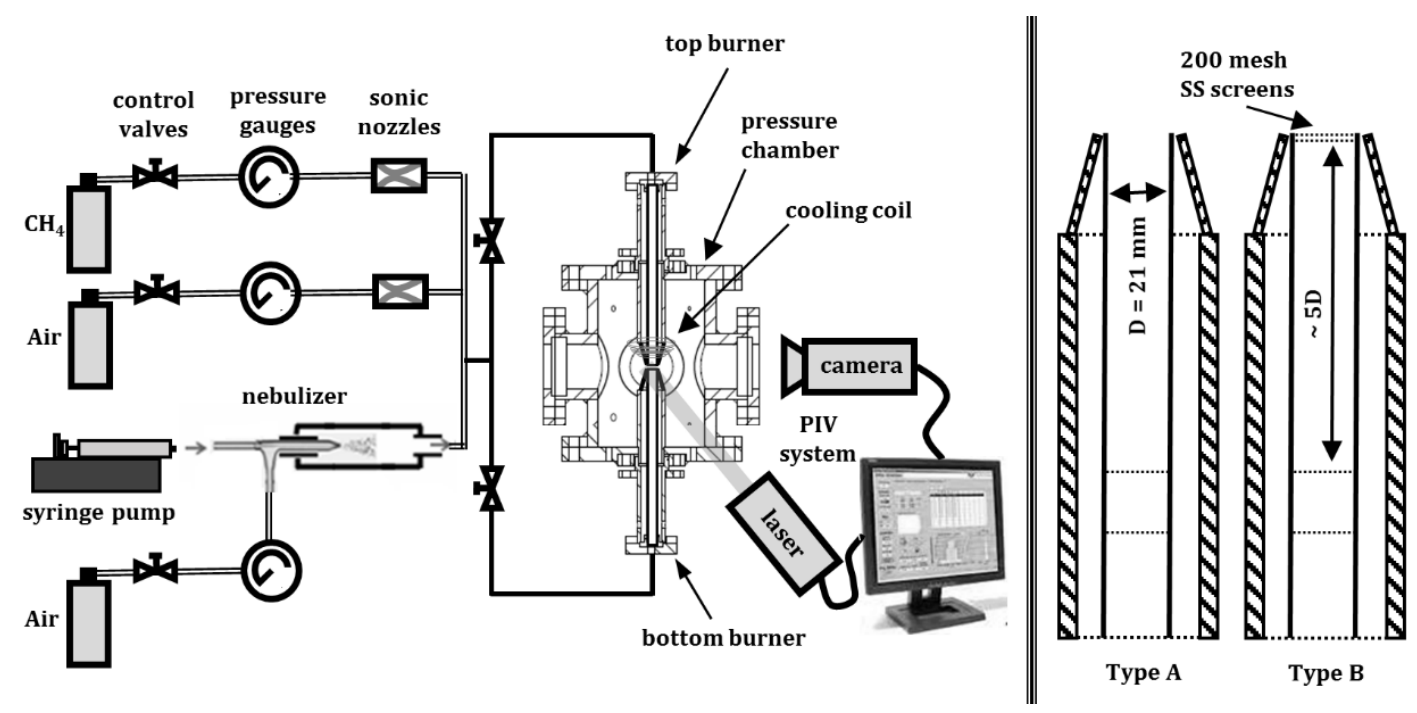

Figure 1: Schematic of the experimental system as configured for symmetric, premixed flames.
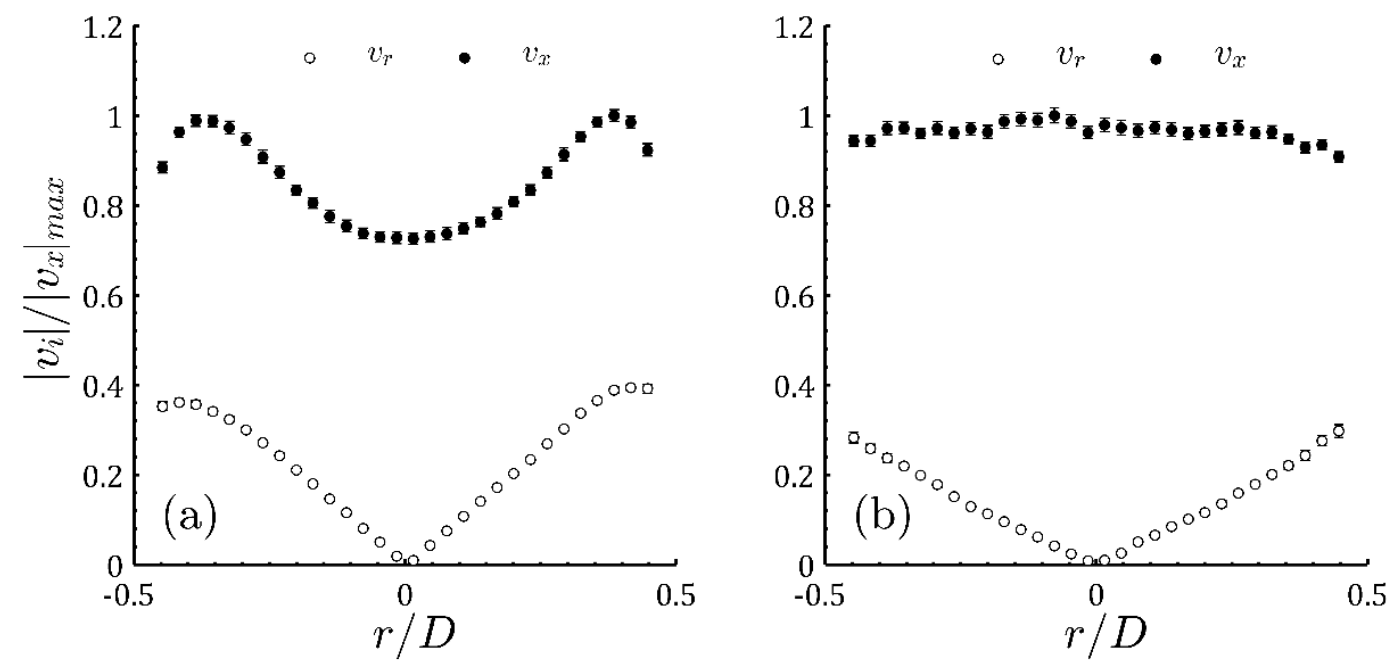

Figure 2: Reacting flow velocity profiles measured $1 \mathrm{~mm}$ from the burner exit near extinction for $\phi=0.542$ : (a) Type A and (b) Type B burners. 

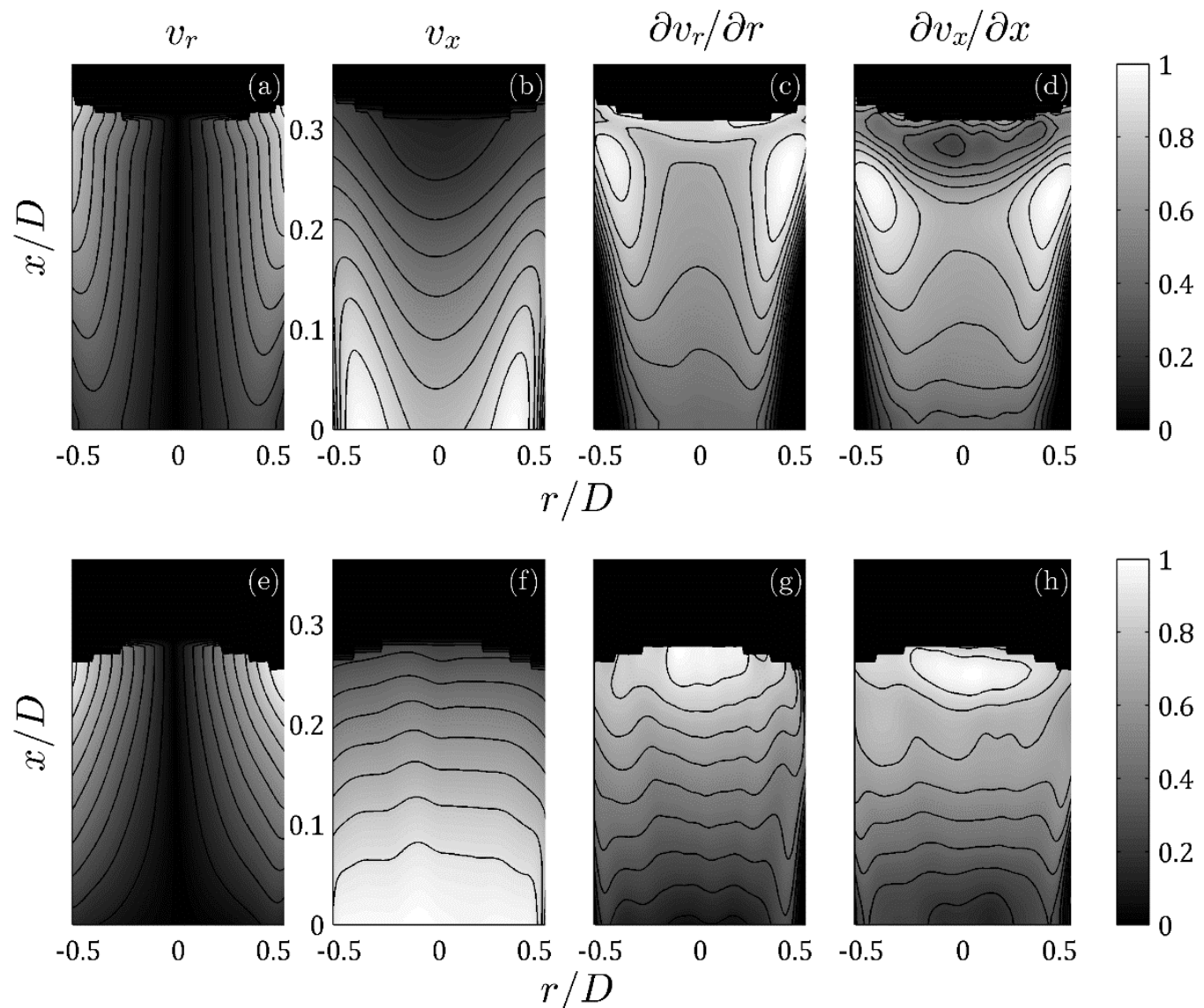

Figure 3: Comparison of normalized flow field structure near extinction for $\phi=0.542$ Type A burner (a-d) and Type B burners (e-h). Lightest (darkest) color corresponds to maximum (minimum) value. 


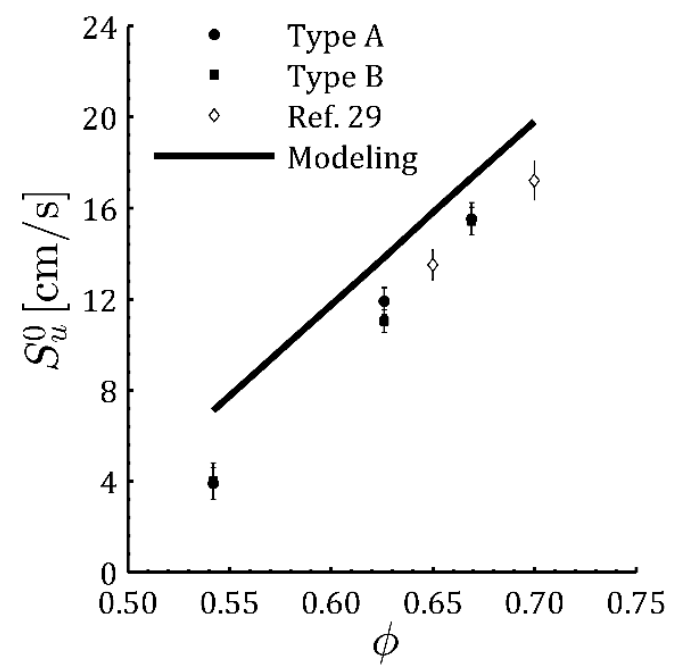

Figure 4: Experimental and computed laminar flame speeds of $\mathrm{CH}_{4} /$ air mixtures.
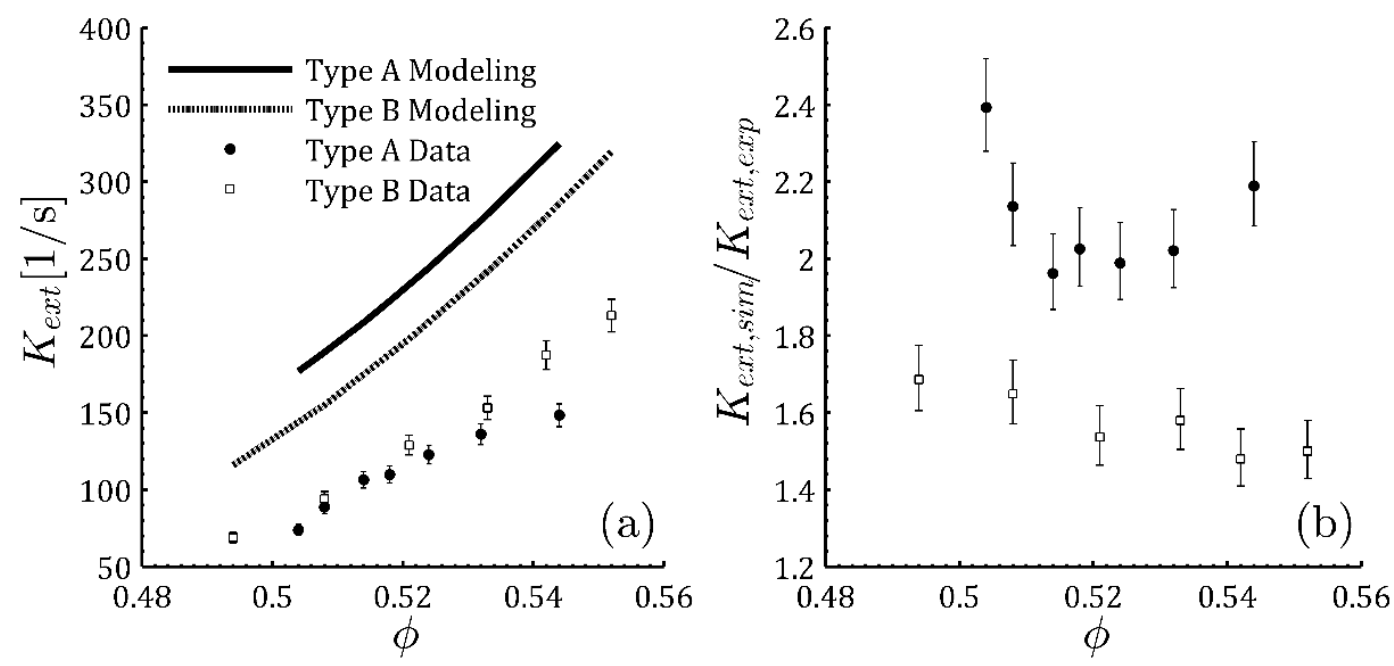

Figure 5: Extinction strain rates of premixed $\mathrm{CH}_{4} /$ air mixtures: (a) measured and computed results and (b) ratio of computed to measured values. 


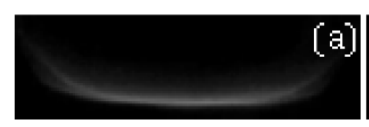

$t \leq 0 \mathrm{me}$

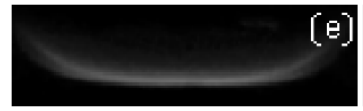

$t \leq 0 \mathrm{me}$

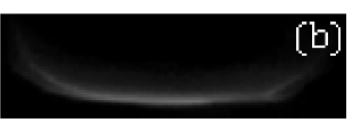

$t=10 \mathrm{~ms}$

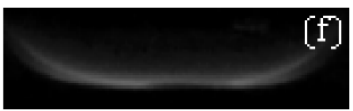

$t=5 \mathrm{me}$

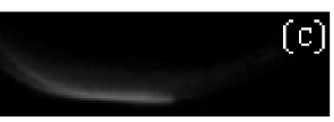

$t=20 \mathrm{~ms}$

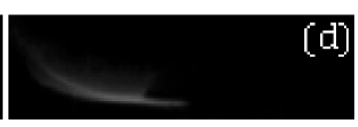

$t=40 \mathrm{me}$

Figure 6: Evolution of the extinction process for lean $\mathrm{CH}_{4} /$ air flames produced by Type A (a-d) and Type B (e-h) burners.
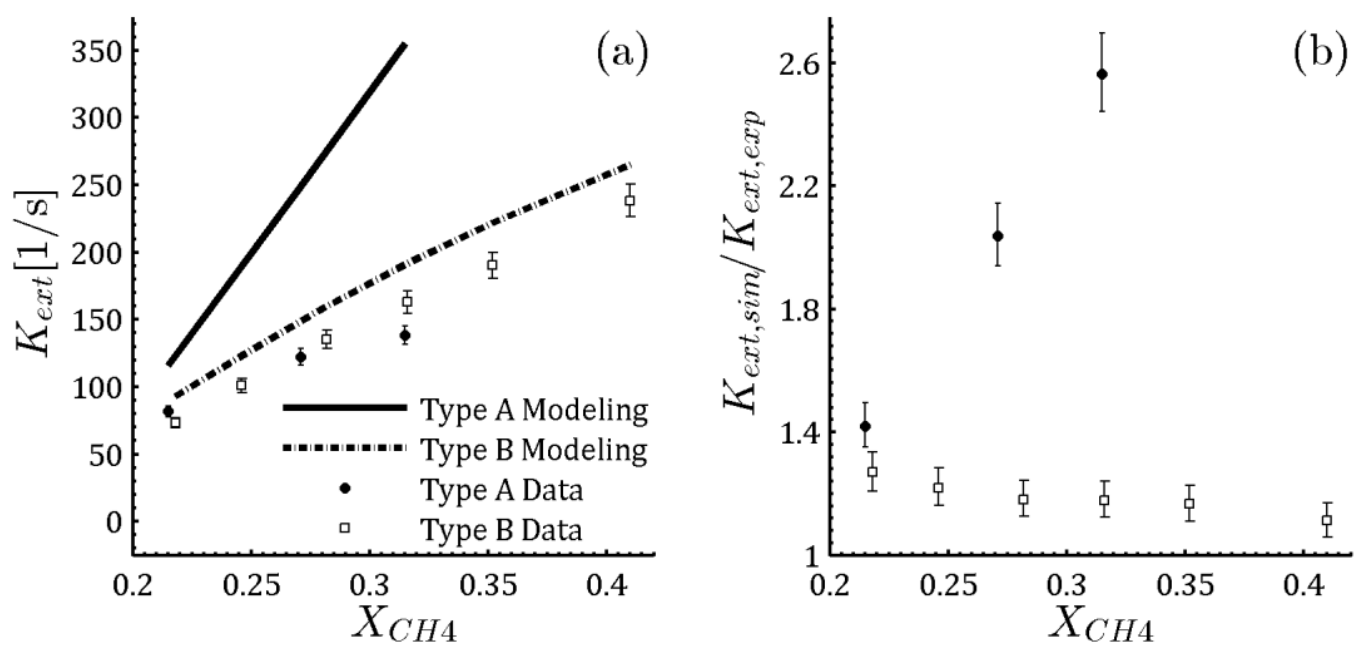

Figure 7: Extinction strain rates of non-premixed $\mathrm{CH}_{4}-\mathrm{N}_{2} /$ air flames. (a) measured and computed results and (b) ratio of computed to measured values. 